\title{
Multimodality treatment of malignant pleural mesothelioma
}

\section{[version 1; peer review: 2 approved]}

\author{
Lawek Berzenji (D), Paul Van Schil (D) \\ Department of Thoracic and Vascular Surgery, Antwerp University Hospital, Wilrijkstraat 10, B-2650 Edegem (Antwerp), Belgium
}

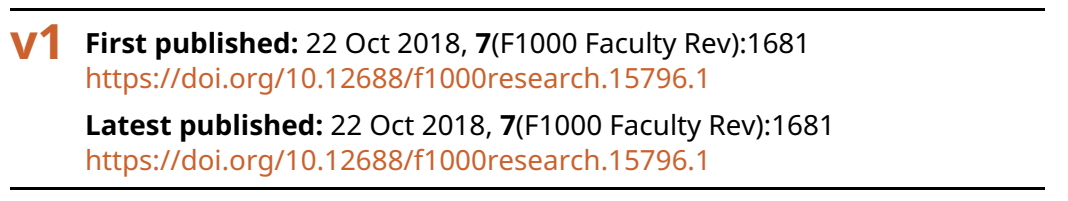

\section{Abstract}

Malignant pleural mesothelioma (MPM) is a rare disease of the pleura and is largely related to asbestos exposure. Despite recent advancements in technologies and a greater understanding of the disease, the prognosis of MPM remains poor; the median overall survival rate is about 6 to 9 months in untreated patients. The main therapeutic strategies for MPM are surgery, chemotherapy, and radiation therapy (RT). The two main surgical approaches for MPM are extrapleural pneumonectomy (EPP), in which the lung is removed en bloc, and pleurectomy/decortication, in which the lung stays in situ. Chemotherapy usually consists of a platinum-based chemotherapy, such as cisplatin, often combined with a folate antimetabolite, such as pemetrexed. More recently, immunotherapy has emerged as a possible therapeutic strategy for MPM. Evidence suggests that singlemodality treatments are not an effective therapeutic approach for MPM. Therefore, researchers have started to explore different multimodality treatment approaches, in which often combinations of surgery, chemotherapy, immunotherapy, and RT are investigated. There is still no definitive answer to the question of which multimodality treatment combinations are most effective in improving the poor prognosis of MPM. Research into the effects of trimodality treatment approaches have found that radical approaches such as EPP and hemithoracic RT post-EPP are less effective than was previously assumed. In general, there are still a great number of unanswered questions and unknown factors regarding the ideal treatment approach for MPM. Hopefully, more research into multimodality therapy will provide insight into which combination of treatment modalities is most effective.

Keywords

Mesotheliomal, Multimodality treatment, Trimodality treatment

\section{Open Peer Review}

Approval Status

1

2

version 1

22 Oct 2018

Faculty Reviews are review articles written by the prestigious Members of Faculty Opinions. The articles are commissioned and peer reviewed before publication to ensure that the final, published version is comprehensive and accessible. The reviewers who approved the final version are listed with their names and affiliations.

\section{Michele Maio, Medical Oncology and} Immunotherapy, Siena, Italy

Luana Calabro, Center for ImmunoOncology, University Hospital of Siena, Istituto Toscano Tumori, Siena, Italy

2. Sonja Klebe, Department of Surgical Pathology, Adelaide 5001, Australia Any comments on the article can be found at the end of the article. 
Corresponding author: Paul Van Schil (paul.van.schil@uza.be)

Author roles: Berzenji L: Conceptualization, Validation, Visualization, Writing - Original Draft Preparation, Writing - Review \& Editing; Van Schil P: Conceptualization, Validation, Visualization, Writing - Original Draft Preparation, Writing - Review \& Editing

Competing interests: No competing interests were disclosed.

Grant information: The author(s) declared that no grants were involved in supporting this work.

Copyright: ( 2018 Berzenji L and Van Schil P. This is an open access article distributed under the terms of the Creative Commons Attribution License, which permits unrestricted use, distribution, and reproduction in any medium, provided the original work is properly cited.

How to cite this article: Berzenji $L$ and Van Schil P. Multimodality treatment of malignant pleural mesothelioma [version 1; peer review: 2 approved] F1000Research 2018, 7(F1000 Faculty Rev):1681 https://doi.org/10.12688/f1000research.15796.1

First published: 22 Oct 2018, 7(F1000 Faculty Rev):1681 https://doi.org/10.12688/f1000research.15796.1 


\section{Introduction}

Malignant mesothelioma is a rare malignant tumor arising from serosal surfaces that can affect the pleura, peritoneum, tunica vaginalis, and pericardium. The most common type is malignant pleural mesothelioma (MPM), which accounts for about $65 \%$ of all malignant mesotheliomas ${ }^{1,2}$. The three major histological subtypes are the epithelioid, sarcomatoid, and biphasic mesotheliomas, and the epithelioid type is the most prevalent ${ }^{3,4}$. For more ambiguous cases of biphasic mesotheliomas, the concept of a "transitional" subtype has been proposed. This subtype applies mainly to cases in which there is ambiguity in quantifying sarcomatoid components in biphasic mesotheliomas ${ }^{5}$. MPM has a peak incidence in the fifth and sixth decades of life and is more common in men than in women ${ }^{6}$. It has been shown that the majority of cases of MPM are related to exposure to amphibole asbestos. A number of other possible etiologies such as simian virus-40, upregulation of mitogen-activated protein kinases, and DNA damage by iron-related reactive oxygen species have also been investigated ${ }^{7}$.

Although MPM is a relatively rare malignancy, the incidence has slightly increased over the last decade because of a lag time in tumor development of 30 to 50 years post-exposure to asbestos. The reported incidence is highest in industrialized countries (up to 30 cases per million), especially in countries such as the UK, Australia, and Belgium, where asbestos was widely used in many industries in the past ${ }^{8}$. Although many developed countries have issued bans on using asbestos in professional environments, exposure to asbestos is still possible because of a rise in do-it-yourself renovations of homes containing asbestos ${ }^{9}$. Data on the incidence of MPM in developing and newly industrialized countries are lacking and often difficult to obtain; however, available data show relatively higher incidences in countries such as Brazil, Russia, and China, where regulations around asbestos exposure are less $\operatorname{strict}^{10,11}$. Furthermore, the estimated burden of mesothelioma deaths in many African countries is likely to be much higher than is seen in referenced data ${ }^{12}$. Diagnosis of the disease is often complicated and delayed because MPM often presents with vague symptoms such as pleuritic chest pain, dyspnea, or weight loss or a combination of these. On chest X-rays, relatively large amounts of pleural fluid may be found as well ${ }^{4,13}$. Despite advancements in treatment modalities, the prognosis of malignant mesothelioma is poor; median overall survival rates of epithelioid MPM are between 12 and 27 months after diagnosis. Sarcomatoid and biphasic mesotheliomas have even poorer prognoses than the epithelioid subtype (7-18 months and 8-12 months, respectively $)^{14}$.

Standard work-up for MPM consists of a chest X-ray, computed tomography (CT) scan of the chest and upper abdomen, complete laboratory blood tests, and a thoracentesis with cytological examination of the pleural effusion. CT scans are often combined with positron emission tomography scans to localize possible metastases and to evaluate treatment responses ${ }^{3,8}$. Correct staging of MPM is an important step in determining which treatment modalities would be most effective and appropriate. The tumor, node, and metastasis (TNM) classification as proposed by the International Mesothelioma Interest Group in
1994 was widely used for the staging of MPM. In 2016, the International Association for the Study of Lung Cancer (IASLC) published a revised version of this classification on the basis of a large-scale analysis of an international database of patients. A number of important revisions have been made with regard to the different staging components.

In the eighth TNM classification, tumor stages T1a and T1b have been combined into one category, T1. This revision implies that no longer will a distinction be made between tumors confined only to the parietal (T1a) or with extension to the visceral pleura (T1b). Statistical analyses of the IASLC database of patients with T1a and T1b showed no significant difference in overall survival. As for the $\mathrm{N}$ component, a number of changes were proposed as well. Both ipsilateral intrapleural and extrapleural nodes have been grouped as $\mathrm{N} 1$ disease where previously these were considered separate categories (N1 and N2). Furthermore, the components of N3 disease have been shifted and now are defined as $\mathrm{N} 2$ disease. Both $\mathrm{pN} 1$ and $\mathrm{pN} 2$ are still considered stage III disease. For the $\mathrm{M}$ descriptors, no changes have been proposed for its components; however, only M1 is now considered stage IV disease $\mathrm{e}^{15-18}$.

There are a number of possible treatment modalities for MPM, and the choice of treatment strategy is based on patient-related and disease-related factors. The most common treatment options are surgical resection, chemotherapy, radiation therapy (RT), and immunotherapy. Often a multimodal approach is preferred to increase treatment effectiveness and to obtain an optimal survival rate. Multimodality treatment can be applied in both a curative and a palliative setting ${ }^{8,19}$.

\section{Surgical resection}

Surgery for MPM is indicated mainly in multimodal approaches and in clinical trial settings according to the latest guidelines. In general, there are two main approaches for surgery with radical and curative intent: (extended) pleurectomy/decortication $(\mathrm{P} / \mathrm{D})$ and extrapleural pneumonectomy (EPP) $)^{8,20}$. Initially, these two surgical approaches did not have clear definitions and the extent of these procedures varied greatly between surgeons. Recently, the IASLC proposed a number of definitions for EPP and P/D:

- EPP: en bloc removal of the lung, the parietal and visceral pleura, diaphragm, and pericardium

- Extended P/D: the same procedure as EPP but the lung is left in situ

- P/D: removal of all gross tumor without resection of the diaphragm or the pericardium

- Partial pleurectomy: a partial resection of parietal or visceral pleura or both without removal of all gross tumor ${ }^{15}$

Whether EPP or (extended) P/D is the superior approach for malignant mesothelioma is a hotly debated topic. For a long time, EPP was the most widely used approach because it was considered the only way to obtain a macroscopic 
complete resection. It was hypothesized that EPP was less likely to leave residual tumor cells when compared with P/D; however, more recent studies have shown that in many cases neither EPP nor $\mathrm{P} / \mathrm{D}$ results in complete $\mathrm{R} 0$ resections ${ }^{21}$. In recent years, there has been a shift in preference of surgeons toward an extended P/D instead of EPP. This trend has been supported by a number of studies that have shown significantly lower complication rates, lower peri-operative morbidity and mortality with $\mathrm{P} / \mathrm{D}$, and similar (if not superior) overall survival rates ${ }^{22}$. Moreover, postoperative quality of life $(\mathrm{QoL})$ seems to be worse in patients after EPP when compared with P/D because of higher rates of complications such as pleural empyema and bronchopleural fistula $^{23,24}$.

\section{Chemotherapy}

Chemotherapy plays an important role in the management of MPM. The standard systemic therapy consists of a combination of cisplatin and pemetrexed or cisplatin and raltitrexed ${ }^{19}$. In some cases, such as in elderly patients, carboplatin may be used as a valid alternative to cisplatin ${ }^{25}$. Cisplatin interferes with DNA replication, and pemetrexed is a folate antimetabolite that works by interfering with nucleic acid synthesis ${ }^{19,26}$. Peri-operative chemotherapy is used for MPM with the goal of increasing local and systemic control of the disease. Furthermore, cisplatin and pemetrexed are used as a pre-operative (induction) treatment to decrease tumor volume and to increase the chances of a more complete resection. The combination of cisplatin and pemetrexed has been used in the majority of clinical studies and has also been combined with surgery and RT in evaluating trimodality therapies s $^{3,8,19}$. A number of single-arm phase II studies have investigated the effects of trimodality therapy and have shown promising results ${ }^{27,28}$. However, despite these results, data from the National Cancer Database (NCDB) show that the frequency of trimodality therapy has not increased significantly in the US, even though the use of chemotherapy with or without surgery has increased ${ }^{29}$. As second-line treatment, chemotherapeutic agents such as gemcitabine, vinorelbine, and pemetrexed are used as well, even though evidence is lacking. In the recent LUME-Meso study, the combination of nintedanib and cisplatin/pemetrexed was evaluated in a phase II randomized, placebo-controlled trial. The results showed an improvement in progression-free survival for the treatment arm, and recruitment for a phase III trial has already started ${ }^{30}$. Another recent randomized controlled study focusing on second-line therapy is the MAPS-2 trial, in which patients with progression after first-line cisplatin/pemetrexed were randomly assigned to one of two groups. One group received nivolumab monotherapy and the other group a combination of nivolumab and ipilimumab. The primary endpoint was disease control rate at 12 weeks, and both treatment arms of this trial reached this endpoint ${ }^{31}$.

\section{Radiation therapy}

RT is not (yet) considered a standard treatment in the setting of MPM, and literature on this topic is relatively scarce. The aim of RT is to maximize tumor control rates with minimal damage to surrounding normal tissue. It can also be used as an adjuvant therapy after surgery or as part of a trimodality approach. For example, after non-lung-sparing surgery (EPP), hemithoracic adjuvant RT may be offered to patients ${ }^{8,32}$. Moreover, in a palliative setting, RT can be applied to reduce chest wall pain ${ }^{33}$. Technological developments in this field such as intensitymodulated radiotherapy may increase the role of RT in the treatment of MPM. The IMPRINT and SMART trials are examples of a possible and safe therapeutic benefit of RT within a multimodal approach ${ }^{34}$. However, owing to a lack of large clinical studies with definitive results, the role of RT largely remains within the settings of clinical trials and palliation ${ }^{8,19,35}$.

\section{Immunotherapy}

Immunotherapy plays an increasingly important role in the management of malignancies. It acts by inhibiting immune checkpoints such as cytotoxic T-lymphocyte antigen 4 (CTLA4 ) or programmed cell death protein-1 (PD-1) and its ligand (PD-L1) $)^{36,37}$. Some early clinical phase studies have evaluated the effect of immune checkpoint inhibitors in the management of MPM. The MESOT-TREM-2008 and MESOT-TREM-2012 are two single-center and single-arm trials that have evaluated the effect of tremelimumab, an anti-CTLA-4 monoclonal antibody. In these two trials, clinical activity and acceptable safety profiles were found in MPM patients with progression after chemotherapy ${ }^{38,39}$. However, in the multicenter, randomized, placebo-controlled DETERMINE trial, no significant difference in overall survival and progression-free survival was found between the treatment and placebo groups. The researchers of this trial noted that although monotherapy did not result in a survival benefit, combined CTLA-4 and PD-L1 blockade could result in additional therapeutic benefit. Regarding PD-L1 blockade, a number of important trials have been published or are ongoing. The KEYNOTE-028 trial has shown that the anti-PD-L1 monoclonal antibody pembrolizumab has clinical benefit in a proportion of patients with PD-L1-positive MPM ${ }^{40}$. This has resulted in several phase II trials such as the KEYNOTE-158 basket trial (ClinicalTrials.gov Identifier: NCT02628067), which aims at assessing biomarkers of pembrolizumab response, and the KEYNOTE-139 study (ClinicalTrials.gov Identifier: NCT02399371), which assesses the activity of fixed-dose pembrolizumab as a second-line therapy for MPM. The NIBIT-MESO-1 trial is one of the studies that are designed to investigate the possible therapeutic benefit of combining immunotherapies. This phase II study combines tremelimumab with durvalumab, an anti-PD-L1 monoclonal antibody. In this single-center, non-randomized study, the results seem promising with an acceptable safety profile $^{41}$. Other examples of ongoing trials that are investigating the combination value of PD-1/PD-L1 and CTLA-4 blockade are the previously mentioned MAPS-2 trial and Checkmate $743^{31,42}$.

\section{Multimodal treatments}

A number of non-randomized clinical trials have investigated the feasibility and outcomes of trimodality treatments for MPM. Rea et al. have evaluated the effects of induction chemotherapy with three or four cycles of carboplatin/gemcitabine, EPP, and postoperative RT in a prospective study with 21 patients $^{43}$. Their results showed a median overall survival rate of 25.5 months and demonstrated that a combined multimodal approach is feasible ${ }^{43}$. Another trial investigating trimodality therapy was published 
by Yamanaka et al. $^{44}$. In this phase II study, 42 patients were enrolled and treated with induction chemotherapy using cisplatin/pemetrexed, EPP, and postoperative hemithoracic RT. In total, 17 patients received trimodality therapy and the overall median survival time for this group was 39.4 months. The overall median survival time for all 42 patients who were enrolled in the study was 19.9 months. However, relapse patterns were similar for patients with or without postoperative RT in this trial. The authors have emphasized that although trimodality therapy seemed feasible, the risk-to-benefit ratio was unsatisfactory ${ }^{44}$. A similar study was set up by the European Organisation for Research and Treatment of Cancer (EORTC) and 59 patients were enrolled. In total, 37 patients received trimodality therapy consisting of induction chemotherapy with cisplatin/pemetrexed, EPP, and postoperative RT. In this study, trimodality treatment was deemed feasible in selected patients with early stage mesothelioma when used in institutions with high levels of expertise and in prospective clinical trials ${ }^{28}$.

Until now, two randomized controlled trials have evaluated the effects of multimodality treatments. In the first trial, Treasure et al. compared the effects of EPP plus postoperative hemithoracic RT versus standard (non-radical) therapy alone following platinum-based chemotherapy. In this MARS 1 study, 50 patients were deemed eligible for randomization: 24 patients were assigned to the EPP arm and 26 to the standard therapy arm. In the end, 16 out of 24 patients completed their treatment with EPP. The median overall survival in the EPP arm was 14.4 months from randomization, and in the non-EPP arm the overall survival was 19.5 months. Furthermore, the EPP arm was also associated with higher morbidity and more serious adverse events than the non-EPP arm. The authors suggested after these findings that a radical approach with EPP offered no benefit when compared with a non-radical approach ${ }^{45}$.

The second randomized clinical trial evaluated the effects of hemithoracic radiotherapy after neoadjuvant chemotherapy and EPP. In total, 54 patients were deemed eligible for randomization: 27 patients were assigned to the RT arm and 27 to the non-RT arm. The overall median survival in both groups was about 20 months. Furthermore, QoL in both patient groups was evaluated, and patients in the non-RT arm reported improvements in physical and psychological symptom distress and activity impairment. After their treatment, patients enrolled in the RT arm reported stable scores in these domains except for activity impairment, which worsened in the first 4 weeks following randomization; however, this stabilized to baseline scores afterwards. In general, their findings did not support the routine use of hemithoracic RT after neoadjuvant chemotherapy and $\mathrm{EPP}^{46}$.

Currently, a number of ongoing trials are investigating the effects of multimodal therapies. MARS 2 (ClinicalTrials.gov Identifier: NCT02040272) is a randomized controlled trial that compares the outcomes of platinum-based chemotherapy plus P/D versus chemotherapy alone. Another clinical study currently being conducted is the EORTC 1205 trial (ClinicalTrials.gov Identifier: NCT02436733), a phase I randomized trial that compares an immediate surgery arm consisting of P/D followed by three cycles of cisplatin/pemetrexed with delayed surgery starting with the same chemotherapeutic regimen followed by P/D. These trials differ from the previously discussed studies that have incorporated surgery in the multimodal approach in that, in the former, P/D instead of EPP is used as surgical treatment ${ }^{19}$.

In the near future, immunotherapy may play a larger part in the multimodal treatment approach of MPM as well. Currently, the combination of immunotherapy, surgical resection, and chemotherapy is also being investigated in an ongoing trial (ClinicalTrials.gov Identifier: NCT02707666). In this single-center, single-arm trial, pembrolizumab is administered in three cycles followed by $\mathrm{P} / \mathrm{D}$ and postoperative chemotherapy with cisplatin/ pemetrexed. Another ongoing trial (ClinicalTrials.gov Identifier: NCT02592551) is investigating the effects of durvalumab and durvalumab plus tremelimumab before resection surgery (EPP or $\mathrm{P} / \mathrm{D}$ ) in a randomized controlled trial. A number of other promising treatment modalities are currently being investigated within a multimodal approach, such as photodynamic therapy (ClinicalTrials.gov Identifier: NCT02662504), arginine deprivation (ClinicalTrials.gov Identifier: NCT02709512), and immunogene therapy (ClinicalTrials.gov Identifier: NCT01119664).

\section{Discussion}

Multimodality treatment for MPM is a topic that has been attracting a lot of attention from researchers in the last couple of years, as therapeutic modalities such as surgery, chemotherapy, or radiotherapy have not proven to be effective as single-modality treatments. Many studies have investigated the effects of multimodal approaches; however, in many cases, the quality of published evidence is poor and underpowered ${ }^{28,47}$. In recent years, larger, multicenter, randomized trials have been started with the aim of reaching a consensus on effective treatment approaches. These studies induced a number of trends (for example, the shift from more radical approaches such as EPP to more conservative treatments such as lung-sparing surgery $\left.[\mathrm{P} / \mathrm{D}]^{21}\right)$. Even randomized controlled trials such as those by Treasure et al..$^{45,46}$ and Stahel et al. ${ }^{45,46}$ do not provide definite answers; in fact, paradoxically, they add to the surgical controversy resulting in ongoing debates at international conferences.

One of the main issues in studies regarding surgery for MPM is the selection bias that is often present. For the vast majority of patients with MPM, the choice for surgery is based on a large number of criteria such as histology, performance status, age, tumor invasiveness, and tumor bulk. For clinical researchers, this selection bias makes it much more difficult to provide unbiased results from clinical studies ${ }^{48}$. Although there is evidence that cancer-directed surgery for MPM provides a survival benefit, researchers agree that patients should be carefully selected and be considered for clinical trial enrollment ${ }^{49}$. A number of ongoing randomized controlled trials are investigating the role of multimodal treatments with less-invasive surgery (P/D). The results from these trials may prove to be valuable in establishing a definitive role for chemotherapy, RT, and lung-sparing surgery in the treatment of MPM. 
Furthermore, trials including immunotherapy such as pembrolizumab, tremelimumab, and durvalumab represent a brand-new area that very likely will be a topic of interest in the next decade. As of now, a number of ongoing trials have combined immunotherapy with chemotherapy or surgery or both. The DREAM trial is an example of a phase II study evaluating the effects of immunotherapy, more specifically durvalumab, combined with cisplatin/pemetrexed. New therapeutic approaches for MPM are on the rise as well. Treatment modalities such as microRNA-loaded minicells targeting epidermal growth factor receptor (EGFR) for tumor suppression, Wilms' tumor 1 vaccines, and tyrosine kinase inhibitors could prove to be valuable additions to the standard therapeutic approaches for MPM $^{34,50}$.

Besides research into treatment modalities for MPM, developments in tumor measurement and response assessment are critically important. Recently, the revised mRECIST (modified response evaluation criteria in solid tumors) were published $^{51}$. These criteria help in establishing international guidelines for the measurement of tumors and response assessments for MPM. With these guidelines, inaccuracies and inconsistencies across clinical trials will be minimized. This allows results from clinical studies to be more robust and uniform, thus allowing more precise comparisons between different studies. Hopefully, these new advances in imaging, staging, and multimodality therapy will improve the grim prognosis of MPM without compromising the QoL of these patients, who still have a limited life expectancy.

Grant information

The author(s) declared that no grants were involved in supporting this work.
1. Bridda A, Padoan I, Mencarelli R, et al.: Peritoneal mesothelioma: a review. MedGenMed. 2007; 9(2): 32 PubMed Abstract | Free Full Text

2. Robinson BW, Lake RA: Advances in malignant mesothelioma. N Engl J Med. 2005; 353(15): 1591-603 PubMed Abstract | Publisher Full Text

3. Shersher DD, Liptay MJ: Multimodality treatment of pleural mesothelioma. Surg Oncol Clin N Am. 2013; 22(2): 345-55. PubMed Abstract

4. Campbell NP, Kindler HL: Update on malignant pleural mesothelioma. Semin Respir Crit Care Med. 2011; 32(1): 102-10. PubMed Abstract | Publisher Full Text

5. F Galateau Salle F, Le Stang N, Nicholson AG, et al.: New Insights on Diagnostic Reproducibility of Biphasic Mesotheliomas: A Multi-Institutional Evaluation by the International Mesothelioma Panel From the MESOPATH Reference Center. J Thorac Oncol. 2018; 13(8): 1189-203. PubMed Abstract | Publisher Full Text | F1000 Recommendation

6. Mott FE: Mesothelioma: a review. Ochsner J. 2012; 12(1): 70-9. PubMed Abstract | Free Full Text

7. Robinson BM: Malignant pleural mesothelioma: an epidemiological perspective. Ann Cardiothorac Surg. 2012; 1(4): 491-6. PubMed Abstract | Publisher Full Text | Free Full Text

8. Baas P, Fennell D, Kerr KM, et al:: Malignant pleural mesothelioma: ESMO Clinical Practice Guidelines for diagnosis, treatment and follow-up. Ann Oncol. 2015; 26 Suppl 5: v31-9.

PubMed Abstract | Publisher Full Text

9. Olsen NJ, Franklin PJ, Reid A, et al.: Increasing incidence of malignant mesothelioma after exposure to asbestos during home maintenance and renovation. Med J Aust. 2011; 195(5): 271-4. PubMed Abstract | Publisher Full Text

10. Frank AL, Joshi TK: The global spread of asbestos. Ann Glob Health. 2014; 80(4): 257-62. PubMed Abstract

11. Hashim D, Boffetta $P$ : Occupational and environmental exposures and cancers in developing countries. Ann Glob Health. 2014; 80(5): 393-411. PubMed Abstract

12. $\mathrm{F}$ Odgerel $\mathrm{CO}$, Takahashi $\mathrm{K}$, Sorahan $\mathrm{T}$, et al.: Estimation of the global burden of mesothelioma deaths from incomplete national mortality data. Occup Environ Med. 2017; 74(12): 851-8.

PubMed Abstract | Publisher Full Text | Free Full Text | F1000 Recommendation

13. Chapman E, Berenstein EG, Diéguez M, et al.: Radiotherapy for malignant pleural mesothelioma. Cochrane Database Syst Rev. 2006; (3): CD003880. PubMed Abstract | Publisher Full Text

14. F Yap TA, Aerts JG, Popat S, et al.: Novel insights into mesothelioma biology and implications for therapy. Nat Rev Cancer. 2017; 17(8): 475-88. PubMed Abstract | Publisher Full Text | F1000 Recommendation

15. F Rusch VW, Chansky K, Kindler HL, et al:: The IASLC Mesothelioma Staging Project: Proposals for the M Descriptors and for Revision of the TNM Stage Groupings in the Forthcoming (Eighth) Edition of the TNM Classification for Mesothelioma. J Thorac Oncol. 2016; 11(12): 2112-9. PubMed Abstract | Publisher Full Text | F1000 Recommendation

16. F Rice D, Chansky K, Nowak A, et al:: The IASLC Mesothelioma Staging Project: Proposals for Revisions of the N Descriptors in the Forthcoming Eighth Edition of the TNM Classification for Pleural Mesothelioma. J Thorac Oncol. 2016; 11(12): 2100-11.

PubMed Abstract | Publisher Full Text | F1000 Recommendation

17. F Nowak AK, Chansky K, Rice DC, et al:: The IASLC Mesothelioma Staging Project: Proposals for Revisions of the T Descriptors in the Forthcoming Eighth Edition of the TNM Classification for Pleural Mesothelioma. J Thorac Oncol. 2016; 11(12): 2089-99.

PubMed Abstract | Publisher Full Text | F1000 Recommendation

18. Berzenji L, Van Schil PE, Carp L: The eighth TNM classification for malignant pleural mesothelioma. Transl Lung Cancer Res. 2018; 7(5): 543-549. Publisher Full Text

19. F Abdel-Rahman O, Elsayed Z, Mohamed H, et al.: Radical multimodality therapy for malignant pleural mesothelioma. Cochrane Database Syst Rev. 2018; 1: CD012605.

PubMed Abstract | Publisher Full Text | F1000 Recommendation

20. F Batirel HF: Extrapleural pneumonectomy (EPP) vs. pleurectomy decortication (P/D). Ann Transl Med. 2017; 5(11): 232. PubMed Abstract | Publisher Full Text | Free Full Text | F1000 Recommendation

21. Domen A, Berzenji L, Hendriks JMH, et al.: Extrapleural pneumonectomy: still indicated? Transl Lung Cancer Res. 2018; 7(5): 550-555. Publisher Full Text

22. Cao C, Tian D, Park J, et al.: A systematic review and meta-analysis of surgical treatments for malignant pleural mesothelioma. Lung Cancer. 2014; 83(2): 240-5.

PubMed Abstract | Publisher Full Text

23. Rena O, Casadio C: Extrapleural pneumonectomy for early stage malignant pleural mesothelioma: a harmful procedure. Lung Cancer. 2012; 77(1): 151-5. PubMed Abstract | Publisher Full Text

24. F Infante M, Morenghi E, Bottoni E, et al:: Comorbidity, postoperative morbidity and survival in patients undergoing radical surgery for malignant pleural mesothelioma. Eur J Cardiothorac Surg. 2016; 50(6): 1077-82. PubMed Abstract | Publisher Full Text | F1000 Recommendation

25. Ceresoli GL, Castagneto B, Zucali PA, et al:: Pemetrexed plus carboplatin in elderly patients with malignant pleural mesothelioma: combined analysis of 
two phase II trials. Br J Cancer. 2008; 99(1): 51-6. PubMed Abstract | Publisher Full Text | Free Full Text

26. Manegold C: Pemetrexed (Alimta, MTA, multitargeted antifolate, LY231514) for malignant pleural mesothelioma. Semin Oncol. 2003; 30(4 Suppl 10): 32-6. PubMed Abstract | Publisher Full Text

27. Weder W, Opitz I: Multimodality therapy for malignant pleural mesothelioma. Ann Cardiothorac Surg. 2012; 1(4): 502-7.

PubMed Abstract | Publisher Full Text | Free Full Text

28. Van Schil PE, Baas P, Gaafar R, et al:: Trimodality therapy for malignant pleura mesothelioma: results from an EORTC phase II multicentre trial. Eur Respir J. 2010; 36(6): 1362-9.

PubMed Abstract | Publisher Full Text

29. F Nelson DB, Rice DC, Niu J, et al:: Predictors of trimodality therapy and trends in therapy for malignant pleural mesothelioma. Eur $J$ Cardiothorac Surg. 2018; 53(5): 960-6.

PubMed Abstract | Publisher Full Text | F1000 Recommendation

30. F Grosso F, Steele N, Novello S, et al:: Nintedanib Plus Pemetrexed/Cisplatin in Patients With Malignant Pleural Mesothelioma: Phase II Results From the Randomized, Placebo-Controlled LUME-Meso Trial. J Clin Oncol. 2017; 35(31): 3591-600.

PubMed Abstract | Publisher Full Text | F1000 Recommendation

31. Scherpereel A, Mazieres J, Greillier L, et al.: Second- or third-line nivolumab (Nivo) versus nivo plus ipilimumab (Ipi) in malignant pleural mesothelioma (MPM) patients: Results of the IFCT-1501 MAPS2 randomized phase II trial. JCO. 2017; 35(18 suppl): LBA8507. Publisher Full Text

32. F Abdel-Rahman O: Role of postoperative radiotherapy in the management of malignant pleural mesothelioma: A propensity score matching of the SEER database. Strahlenther Onkol. 2017; 193(4): 276-84.

PubMed Abstract | Publisher Full Text | F1000 Recommendation

33. $\mathrm{F}$ Kindler HL, Ismaila N, Armato SG 3rd, et al:: Treatment of Malignant Pleural Mesothelioma: American Society of Clinical Oncology Clinical Practice Guideline. J Clin Oncol. 2018; 36(13): 1343-73.

PubMed Abstract | Publisher Full Text | F1000 Recommendation

34. F Mutti L, Peikert T, Robinson BWS, et al.: Scientific Advances and New Frontiers in Mesothelioma Therapeutics. J Thorac Oncol. 2018; 13(9): 1269-83. PubMed Abstract | Publisher Full Text | F1000 Recommendation

35. Runxiao L, Yankun C, Lan W: A pilot study of volumetric-modulated arc therapy for malignant pleural mesothelioma. J App/ Clin Med Phys. 2016; 17(2): 139-44. PubMed Abstract | Publisher Full Text | Free Full Text

36. F Nguyen BH, Montgomery R, Fadia M, et al.: PD-L1 expression associated with worse survival outcome in malignant pleural mesothelioma. Asia Pac $J$ Clin Oncol. 2018; 14(1): 69-73.

PubMed Abstract | Publisher Full Text | F1000 Recommendation

37. F Guazzelli A, Bakker E, Krstic-Demonacos M, et al:: Anti-CTLA-4 therapy for malignant mesothelioma. Immunotherapy. 2017; 9(3): 273-80. PubMed Abstract | Publisher Full Text | F1000 Recommendation

38. Calabrò L, Morra A, Fonsatti E, et al.: Tremelimumab for patients with chemotherapy-resistant advanced malignant mesothelioma: An open-label, single-arm, phase 2 trial. Lancet Oncol. 2013; 14(11): 1104-11. PubMed Abstract | Publisher Full Text

39. Calabrò L, Morra A, Fonsatti $E$, et al. Efficacy and safety of an intensified schedule of tremelimumab for chemotherapy-resistant malignant mesothelioma: An open-label, single-arm, phase 2 study. Lancet Respir Med.
$2015 ; 3(4): 301-9$

PubMed Abstract | Publisher Full Text

40. F Alley EW, Lopez J, Santoro A, et al.: Clinical safety and activity of pembrolizumab in patients with malignant pleural mesothelioma (KEYNOTE028): preliminary results from a non-randomised, open-label, phase $1 \mathrm{~b}$ trial. Lancet Oncol. 2017; 18(5): 623-30.

PubMed Abstract | Publisher Full Text | F1000 Recommendation

41. F Calabrò L, Morra A, Giannarelli D, et al:: Tremelimumab combined with durvalumab in patients with mesothelioma (NIBIT-MESO-1): an open-label, non-randomised, phase 2 study. Lancet Respir Med. 2018; 6(6): 451-60. PubMed Abstract | Publisher Full Text | F1000 Recommendation

42. Zalcman G, Peters S, Mansfield AS, et al.: Checkmate 743: A phase 3, randomized, open-label trial of nivolumab (nivo) plus ipilimumab (ipi) vs pemetrexed plus cisplatin or carboplatin as first-line therapy in unresectable pleural mesothelioma. JCO. 2017; 35: TPS8581. Publisher Full Text

43. Rea F, Marulli G, Bortolotti L, et al.: Induction chemotherapy, extrapleural pneumonectomy (EPP) and adjuvant hemi-thoracic radiation in malignant pleural mesothelioma (MPM): Feasibility and results. Lung Cancer. 2007; 57(1): 89-95. PubMed Abstract | Publisher Full Text

44. Yamanaka T, Tanaka F, Hasegawa S, et al:: A feasibility study of induction pemetrexed plus cisplatin followed by extrapleural pneumonectomy and postoperative hemithoracic radiation for malignant pleural mesothelioma. Jpn $J$ Clin Oncol. 2009; 39(3): 186-8.

PubMed Abstract | Publisher Full Text

45. Treasure T, Lang-Lazdunski L, Waller D, et al:: Extra-pleural pneumonectomy versus no extra-pleural pneumonectomy for patients with malignant pleural mesothelioma: clinical outcomes of the Mesothelioma and Radical Surgery (MARS) randomised feasibility study. Lancet Oncol. 2011; 12(8): 763-72. PubMed Abstract | Publisher Full Text | Free Full Text

46. F Stahel RA, Riesterer O, Xyrafas A, et al:: Neoadjuvant chemotherapy and extrapleural pneumonectomy of malignant pleural mesothelioma with or without hemithoracic radiotherapy (SAKK 17/04): a randomised, international, multicentre phase 2 trial. Lancet Oncol. 2015; 16(16): 1651-8. PubMed Abstract | Publisher Full Text | F1000 Recommendation

47. Singhal S, Kaiser LR: Malignant mesothelioma: options for management. Surg Clin North Am. 2002; 82(4): 797-831. PubMed Abstract | Publisher Full Text

48. Datta A, Smith R, Fiorentino F, et al.: Surgery in the treatment of malignant pleural mesothelioma: recruitment into trials should be the default position. Thorax. 2014; 69(2): 194-7.

PubMed Abstract | Publisher Full Text | Free Full Text

49. $\quad$ F Nelson DB, Rice DC, Niu J, et al.: Long-Term Survival Outcomes of CancerDirected Surgery for Malignant Pleural Mesothelioma: Propensity Score Matching Analysis. J Clin Oncol. 2017; 35(29): 3354-62. PubMed Abstract | Publisher Full Text | F1000 Recommendation

50. F van Zandwijk N, Pavlakis N, Kao SC, et al.: Safety and activity of microRNAloaded minicells in patients with recurrent malignant pleural mesothelioma: a first-in-man, phase 1, open-label, dose-escalation study. Lancet Oncol. 2017; 18(10): 1386-96.

PubMed Abstract | Publisher Full Text | F1000 Recommendation

51. F Armato SG 3rd, Nowak AK: Revised Modified Response Evaluation Criteria in Solid Tumors for Assessment of Response in Malignant Pleural Mesothelioma (Version 1.1). J Thorac Oncol. 2018; 13(7): 1012-21. PubMed Abstract | Publisher Full Text | F1000 Recommendation 


\section{Open Peer Review}

\section{Current Peer Review Status:}

\section{Editorial Note on the Review Process}

Faculty Reviews are review articles written by the prestigious Members of Faculty Opinions. The articles are commissioned and peer reviewed before publication to ensure that the final, published version is comprehensive and accessible. The reviewers who approved the final version are listed with their names and affiliations.

\section{The reviewers who approved this article are:}

\section{Version 1}

\section{Sonja Klebe}

SA Pathology at Flinders Medical Centre, Department of Surgical Pathology, Adelaide 5001, Australia

Competing Interests: No competing interests were disclosed.

\section{Michele Maio}

Center for Immuno-Oncology, University Hospital of Siena, Istituto Toscano Tumori, Medical Oncology and Immunotherapy, Siena, Italy

\section{Luana Calabro}

Medical Oncology and Immunotherapy, Center for Immuno-Oncology, University Hospital of Siena, Istituto Toscano Tumori, Siena, Italy

Competing Interests: No competing interests were disclosed.

The benefits of publishing with F1000Research:

- Your article is published within days, with no editorial bias

- You can publish traditional articles, null/negative results, case reports, data notes and more

- The peer review process is transparent and collaborative

- Your article is indexed in PubMed after passing peer review

- Dedicated customer support at every stage

For pre-submission enquiries, contact research@f1000.com 